\title{
A COMPARATIVE STUDY OF CLEANING METHODS FOR TARNISHED SILVER
}

\author{
Teresa Palomar ${ }^{1 *}$, Blanca Ramirez Barat ${ }^{1}$, Emma García $^{2}$, Emilio Cano ${ }^{1}$ \\ ${ }^{1}$ Centro Nacional de Investigaciones Metalúrgicas (CENIM), Consejo Superior de \\ Investigaciones Científicas (CSIC), Av. Gregorio del Amo 8, 28040 Madrid (Spain) \\ ${ }^{2}$ Instituto del Patrimonio Cultural de España (IPCE), Ministerio de Educación, Cultura y Deporte \\ (MECD). Pintor el Greco 4, Ciudad Universitaria, 28040 Madrid (Spain) \\ * Corresponding author: t.palomar@csic.es
}

\begin{abstract}
Tarnishing is produced by reaction of silver with gaseous reduced sulphur compounds from atmospheric pollution. It induces the formation of $\mathrm{Ag}_{2} \mathrm{~S}$ crystals which produce a dark appearance. To remove sulphur tarnishing, different mechanical, chemical and electrochemical methods have been traditionally used. To assess the effect of different cleaning treatments on tarnished silver, coupons of pure and sterling silver $(92 \% \mathrm{Ag} / 8 \% \mathrm{Cu})$ were subjected to six cycles of induced tarnishing and cleaning. The cleaning methods evaluated were mechanical (soft abrasives and rubber point mounted on a rotary tool); chemical (chelating and acid solutions) and electrochemical (potentiostatic reductions). Surface morphology, composition, weight, color and luminosity were evaluated by optical microscopy, scanning electron microscopy/energy dispersive X-ray spectroscopy, atomic force microscopy, X-ray photoelectron spectroscopy and colorimetry. The cleaning impact on tarnished silver depended on the cleaning procedure and the composition of silver. Mechanical treatments restored the original visual appearance of silver although they produced a significant mass loss and a fast retarnishing. Chemical cleaning methods were fast; nevertheless the surface appeared completely attacked. Electrochemical cleaning did not yield good result for sterling silver, but was an effective cleaning method for pure silver coupons.
\end{abstract}

Kevwords: Pure silver, Sterling silver, Tarnishing, Cleaning methods, Conservation, Electrochemistry.

(C) 2016. This manuscript version is made available under the CC-BY-NC-ND 4.0 license http://creativecommons.org/licenses/by-nc-nd/4.0/

Published in Journal of Cultural Heritage (2016) 17, 20-26

https://doi.org/10.1016/j.culher.2015.07.012 


\section{Research aims}

Different cleaning methods have been used for many years to remove sulphur tarnishing from silver. However, scientific studies which assess the treatment's impact on silver and the retarnishing rate are very scarce. Costa [1] carried out a complete bibliographic study about the cleaning procedures and their applications, although the results of these different scientific works are difficult to compare since they have not been systematically evaluated in similar conditions and materials.

The aim of this study is to quantitatively assess the efficiency, residues left on the metal and impact on the base metal of eleven mechanical, chemical and electrochemical cleaning methods to remove tarnishing on pure and sterling silver. To evaluate the effect in the long term, several cycles of tarnishing/cleaning are considered.

\section{Introduction}

Silver artifacts have been valuable objects since ancient times, as a symbol of status and prestige. Jewelry, cutlery, decoration objects and historical coins are the most common silver artifacts exposed in museums and private collections.

The principal alteration of silver exposed to atmospheric environment is tarnishing, which is produced by the reaction of silver surface with gaseous sulphur compounds, such as hydrogen sulphide $\left(\mathrm{H}_{2} \mathrm{~S}\right)$, carbonyl sulphide (OCS) and other organic compounds (Reaction 1 and 2) $[2,3]$. The process is accelerated by the presence of humidity [1]. The tarnishing produced by sulphur dioxide was much slower than that caused by $\mathrm{H}_{2} \mathrm{~S}$ or OCS $[4,5]$. The result is a surface layer of silver sulphide $\left(\mathrm{Ag}_{2} \mathrm{~S}\right)$.

$$
\begin{aligned}
& 2 \mathrm{Ag}+\mathrm{H}_{2} \mathrm{~S}+1 / 2 \mathrm{O}_{2} \rightarrow \mathrm{Ag}_{2} \mathrm{~S}+\mathrm{H}_{2} \mathrm{O} \\
& 2 \mathrm{Ag}+\mathrm{OCS} \rightarrow \mathrm{Ag}_{2} \mathrm{~S}+\mathrm{CO}
\end{aligned}
$$

Although it is a thin layer and the corrosion is usually mild, tarnishing has a huge visual impact, because it changes the whitish brilliant appearance characteristic of silver to a yellowish or brownish mate tone. To recover its original color and brightness several cleaning methods may be used, including mechanical, chemical and electrochemical procedures, with different effectiveness and surface impact.

To identify the usual silver cleaning methods applied by conservators, the bibliographic work of Costa [1] and a consultation carried out amongst metal conservation professionals working in museums and conservation institutions were considered. According to them, mechanical methods are preferred, followed by chemical ones. Other methods such as electrochemical treatments or laser are less used. The majority of professionals employed commercial products which used to be liquids, foams, pastes, waddings or cloths usually made up of an abrasive $\left(\mathrm{SiO}_{2}, \mathrm{Al}_{2} \mathrm{O}_{3}, \mathrm{TiO}_{2}, \mathrm{CaCO}_{3} \ldots\right)$ mixed with organic substances (surfactants, soaps, fatty acids...) [6, 7]. The main disadvantage of commercial products is that their precise composition is unknown, and may be unexpectedly modified by the manufacturer, changing therefore their effectiveness and aggressiveness. 
Pre-lim surface cleaner (Neuburg silica chalks in a water/white spirit emulsion produced by Picreator Enterprises Ltd.) and calcium carbonate are the most favored products for mechanical cleaning. Both are soft abrasives with similar hardness to silver (Mohs' Scale of silver: 2.5-4 and $\mathrm{CaCO}_{3}: 3$ ) [2]. Previous studies confirmed that abrasives such as alumina, quartz or hematite could leave scratches on silver surface due to their higher hardness $[2,6$, 7].

Regarding chemical methods, thiourea acid solutions (also commercially sold as "silver dip") are the most popular amongst conservators. Thiourea acts as a chelating agent, dissolving the tarnished layer according to the reaction 3 [2, 8]. General solvents such as alcohol and acetone, and weak acids such as formic acid and citric acid are also used, in lesser proportion, with moderate efficiency and slow cleaning rate.

$$
\mathrm{Ag}_{2} \mathrm{~S}+2 \mathrm{H}^{+}+2 \mathrm{n}\left[\mathrm{CS}\left(\mathrm{NH}_{2}\right)_{2}\right] \rightarrow 2 \mathrm{Ag}\left[\mathrm{CS}\left(\mathrm{NH}_{2}\right)_{2}\right]_{\mathrm{n}}{ }^{+}+\mathrm{H}_{2} \mathrm{~S}
$$

Electrochemical methods are scarcely used by conservators because they usually require specific equipment. In metal conservation, it is usually distinguished between "electrolytic reduction", when the source of energy is an external source (a battery, generator or potentiostat/galvanostat) and "electrochemical reduction" (or galvanic reduction) when the source of energy is the formation of a galvanic cell between the object acting as cathode and a less noble metal, usually zinc or aluminum, acting as anode [9]. Given all the variations of modern electrochemical techniques (galvanostatic, potentiostatic, potentiodynamic...) and the fact that all them have the same basis, that is, to reverse the oxidation of the metal that caused the degradation of the object, we prefer to use the generic term "electrochemical (cleaning) methods" for all them [1]. Amongst these electrochemical methods, galvanic reduction with aluminum or zinc and an alkaline electrolyte is the most common one, although conservators declare that it leaves non-uniform results. Electrochemical methods were very popular for metal conservation for most of the XX century, but were progressively abandoned in the 1970s-1980s due to the changes in the conservation-restoration criteria [9]. However, developments in the application of electrochemical techniques in the last 20 years have made them popular again for metallic cultural heritage, as conservation treatment [10-12], for analytical purposes [13-16] or to evaluate the efficiency of other conservation-restoration treatments $[9,17-19]$.

The ideal cleaning treatment should remove the tarnished layer without affecting the underlying silver surface. With this premise some scientific studies about the effectiveness of cleaning methods have been carried out on abrasives [6, 7], thiourea-acid solutions [8], electrochemical galvanic cells [20], electrochemical reductions [21,22] and new treatments such as laser [23, 24], cold plasma [25], or UV/Ozone treatment [26]. However, results of different methods are difficult to compare since they have not been systematically evaluated in similar conditions and materials. To obtain a wide perspective of the impact of silver cleaning methods, a systematic comparative study of different cleaning procedures has been done to characterize their impact (cleaning efficiency, surface appearance, mass variation and color) on silver after several cycles of tarnishing and cleaning. 


\section{Materials and methods}

The evaluation of cleaning methods was carried out on pure and sterling silver coupons $(2 \times 1 \times 0.1 \mathrm{~cm})$, abraded with emery paper down to grade 2000 . The original coupons were analyzed by wavelength dispersive X-ray fluorescence (WDXRF), with a Bruker S8 Tiger. Pure silver presented $99.50 \mathrm{wt} \%$ of silver and $0.30 \mathrm{wt} \%$ of iron and sterling silver was $92.47 \mathrm{wt} \%$ of silver and $7.28 \mathrm{wt} \%$ of copper. They were exposed to 6 cycles of tarnishing and cleaning, and they were characterized after each cycle and at the end of the experiment, to assess the cumulative effects of the repetitive cleaning treatments that are applied over decades to silver heritage artefacts.

Tarnishing was carried out by exposure the silver coupons to a sulphur vapor environment at $75 \% \mathrm{RH}$ according to UNE-EN-ISO 4538 standard [27]. Upon exposure to the sulphur vapor environment, samples started to form a yellowish tarnishing after few hours that progressively darkened reaching a brownish appearance after $72 \mathrm{~h}$. This degree of tarnishing was chosen for this study as representative of an advanced tarnishing level that can be found in some cases in real objects.

Cleaning methods were selected amongst the most usual ones utilized in silver conservation practice, and were applied by professional metal conservators following their customary procedures. Eleven cleaning procedures (mechanical, chemical and electrochemical) have been evaluated, both on pure and sterling silver (Table 1). Two soft abrasives and a polishing process were selected as mechanical cleaning methods. The abrasives used were calcium carbonate dispersed in distilled water (MC) and Pre-lim surface cleaner (MP), which were applied with cotton swabs until total apparent removal of tarnishing. The third mechanical method was polishing with a rubber point mounted on a rotary tool and softly abraded with Pre-lim to finish the treatment (MT).

Table 1. Summary of eleven cleaning procedures evaluated.

\begin{tabular}{|c|c|c|}
\hline $\begin{array}{l}\text { Type of } \\
\text { cleaning }\end{array}$ & Abbreviations & Description \\
\hline \multirow{3}{*}{ Mechanical } & $\mathrm{MC}$ & Calcium carbonate \\
\hline & MP & Pre-lim surface cleaner \\
\hline & MT & Rotary tool w/rubber point \\
\hline \multirow{6}{*}{ Chemical } & $\mathrm{CD}$ & DTPA pentasodium salt $10 \% \mathrm{w} / \mathrm{w}+$ Triton $\mathrm{X}-1001.5 \% \mathrm{v} / \mathrm{v}$ \\
\hline & $\mathrm{CT}$ & Thiourea $8 \% \mathrm{w} / \mathrm{w}$ \\
\hline & CE & EDTA $10 \% \mathrm{w} / \mathrm{w}$ \\
\hline & CA & $\mathrm{HCOOH} 10 \% \mathrm{v} / \mathrm{v}$ \\
\hline & $\mathrm{CP}$ & $\begin{array}{l}\text { Thiourea } 8 \% \mathrm{w} / \mathrm{w}+\text { phosphoric acid } 5 \% \mathrm{v} / \mathrm{v}+\text { Triton } \mathrm{X}-1000.5 \% \\
\mathrm{v} / \mathrm{v}\end{array}$ \\
\hline & $\mathrm{CF}$ & Thiourea $8 \% \mathrm{w} / \mathrm{w}+$ formic acid 5\% v/v + Triton X-100 0.5\% v/v \\
\hline \multirow{2}{*}{ Electrochemical } & EN & $-1 \mathrm{~V}_{\mathrm{Ag}-\mathrm{AgCl}}-\mathrm{NaNO}_{3} 0.1 \mathrm{M}$ \\
\hline & ES & $-1 \mathrm{~V}_{\mathrm{Ag}-\mathrm{AgCl}}-\mathrm{Na}{ }_{3} \mathrm{H}\left(\mathrm{CO}_{3}\right)_{2} 0.1 \mathrm{M}$ \\
\hline
\end{tabular}

Six chemical cleaning methods were evaluated by dipping: thiourea $8 \% \mathrm{w} / \mathrm{w}$; EDTA $10 \% \mathrm{w} / \mathrm{w}$; formic acid 10\% v/v; DTPA pentasodium salt 10\% w/w + Triton X-100 1.5\% v/v; thiourea $8 \%$ $\mathrm{w} / \mathrm{w}+$ phosphoric acid $5 \% \mathrm{v} / \mathrm{v}+$ Triton X-100 0.5\% v/v (CP); and thiourea $8 \% \mathrm{w} / \mathrm{w}+$ formic acid 
$5 \% \mathrm{v} / \mathrm{v}+$ Triton $\mathrm{X}-1000.5 \% \mathrm{v} / \mathrm{v}$ (CF), all them in distilled water $[2,8,28]$. Additionally EDTA $10 \%$ $\mathrm{w} / \mathrm{w}$ was evaluated using cotton swabs.

The electrochemical cleaning methods were potentiostatic reductions with a Gamry Ref. 600 for 350 seconds, using $\mathrm{NaNO}_{3} 0.1 \mathrm{M}(\mathrm{EN})$ or $\mathrm{Na}_{3} \mathrm{H}\left(\mathrm{CO}_{3}\right)_{2} 0.1 \mathrm{M}(\mathrm{ES})$ aqueous solutions as electrolytes, and a $\mathrm{Ag} / \mathrm{AgCl}$ reference electrode [22]. To optimize the $\mathrm{Ag}_{2} \mathrm{~S}$ reduction, a potentiodynamic (linear sweep voltammogram) curve of tarnished coupons was carried out for each electrolyte with a potential scan rate of $1 \mathrm{mV} / \mathrm{s}$. The reduction peak potential of $\mathrm{Ag}_{2} \mathrm{~S}$ in $\mathrm{NaNO}_{3}$ was at $-828 \mathrm{mV}_{\mathrm{Ag} / \mathrm{AgCl}}$ and in $\mathrm{Na}_{3} \mathrm{H}\left(\mathrm{CO}_{3}\right)_{2}$ was at $-747 \mathrm{mV} \mathrm{Ag}_{\mathrm{AgCl}}$. In both cases, potentiostatic reductions were carried out at $-1 \mathrm{~V}_{\mathrm{Ag} / \mathrm{AgCl}}$, to assure the complete reduction of corrosion products, while avoiding hydrogen evolution.

The surface of silver coupons was characterized by scanning electron microscopy (SEM), atomic force microscopy (AFM) and X-ray photoelectron spectroscopy (XPS).

The scanning electron (SEM) micrographs were obtained using the secondary electrons detector of a Hitachi S-4800 microscope, equipped with a cold-cathode field emission electron gun and an Oxford INCA system for energy dispersive X-ray spectrometry microanalysis (EDX).

Atomic force microscopy (AFM) observations were made in an Agilent 5500 AFM/SPM microscope in tapping mode. Images show the topographical images of a scan over an area of $10 \times 10 \mu \mathrm{m}$.

Composition of the surface was analyzed by X-ray photoelectron spectroscopy (XPS), using a VG Microtech Model MT 500 spectrophotometer with an Mg Ka1.2 anode X-ray source (hv = $1253.6 \mathrm{eV}$ ), with a primary beam energy of $15 \mathrm{kV}$ and an electron current of $20 \mathrm{~mA}$.

To evaluate the visual impact of the tarnishing, colorimetric measurements were carried out with a Konica Minolta Portable colorimeter model 2500D equipped with a mask of $8 \mathrm{~mm}$ of diameter, D65 as illuminant and at 10 degrees to the observer. The color space was $\mathrm{L}^{*} \mathrm{a}^{*} \mathrm{~b}^{*}$ at $\mathrm{SCl} / \mathrm{SCE}$.

\section{Results and discussion}

\subsection{Silver tarnishing}

Original silver coupons presented linear surface scratches due to sample preparation (Fig. 1 a). After tarnishing, all silver coupons presented a brownish layer related with the formation of corrosion products. On pure silver coupons, sulphur vapor reacted with silver surface and formed spherical crystals (over $25 \mathrm{~nm}$ of diameter) of $\mathrm{Ag}_{2} \mathrm{~S}$ (Fig. $1 \mathrm{~b}$ ). On sterling silver coupons, the surface was covered homogeneously by laminar crystals of $100 \mathrm{~nm}$ of length (Fig. $1 \mathrm{c}$ ). The deposits formed had a similar structure to CuS crystals formed on pure copper (Fig. 1 d), but they were rounder due to the sphericity of $\mathrm{Ag}_{2} \mathrm{~S}$. Surface analysis demonstrated the enrichment of copper on the surface of sterling coupons due to the reaction of sulphur vapor (Fig. 1, analysis A2), indicating a selective corrosion of copper in sterling silver. Standard free energy of formation at room temperature of copper sulphide is lower than silver sulphide, so the reaction of sulphur with copper is thermodynamically favored [29]. 

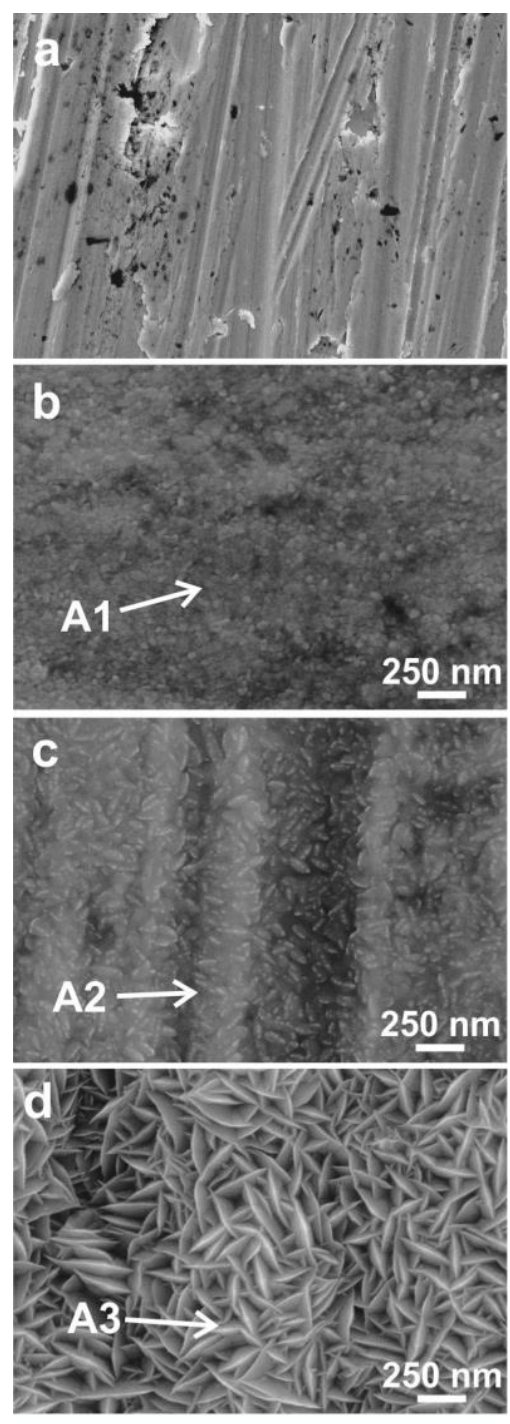

\begin{tabular}{ccrrr}
\hline Analysis & O & \multicolumn{1}{c}{ S } & Cu & Ag \\
\hline A1 & -- & 0,7 & -- & 99,3 \\
A2 & -- & 2,3 & 22,8 & 74,9 \\
A3 & 2,4 & 17,6 & 80,1 & -- \\
\hline
\end{tabular}

Fig. 1. SEM images of the surface of original pure silver (a), tarnished pure silver (b), tarnished sterling silver (c) and sulphidated copper (d). The enclosed table displays EDX microanalysis results (wt. \%).

\subsection{Pure silver cleanings}

Four methods were discarded after the first cleaning cycle because they did not remove the tarnished layer. These methods were thiourea $8 \% \mathrm{w} / \mathrm{w}$, formic acid $10 \% \mathrm{v} / \mathrm{v}$, DTPA pentasodium salt $10 \% \mathrm{w} / \mathrm{w}+$ Triton $\mathrm{X}-1001.5 \% \mathrm{v} / \mathrm{v}$, and EDTA $10 \% \mathrm{w} / \mathrm{w}$. We present here only the results of those methods that were effective in eliminating the sulphide tarnishing.

Mechanical cleanings left the surface smoother than original and tarnished coupons because of the abrasive effect of Pre-lim and calcium carbonate. The visual effect was homogeneous and shiny, although some lineal scratches, related with the abrasives, which were microscopically observed (Fig. 2 a). In the largest holes and scratches, remains of $\mathrm{Ag}_{2} \mathrm{~S}$ were detected because the manual system did not reach to clean them. MT cleaning left irregular marks on the surface due to the rubber point. 
The thiourea-acid solutions ( $C P$ and $C F$ ) removed the tarnished layer of $\mathrm{Ag}_{2} \mathrm{~S}$ in few seconds because thiourea is an excellent chelating agent of silver (Reaction 3). After six cycles of tarnishing and cleaning, the microstructure of pure silver coupons was totally lost and the scratches on the original coupons were widened and deepened creating holes which could retain the thiourea solution (Fig. 2 b). The surface of the coupon cleaned with CF solution was less altered than the coupon cleaned with $\mathrm{CP}$ solution, probably due to the solution $\mathrm{pH}$.

After six cycles of sulphidation-electrochemical cleaning, the sample surface of silver coupons appeared microscopically rough (Fig. $2 \mathrm{C}$ ), because silver was reduced preserving the $\mathrm{Ag}_{2} \mathrm{~S}$ deposits morphology.
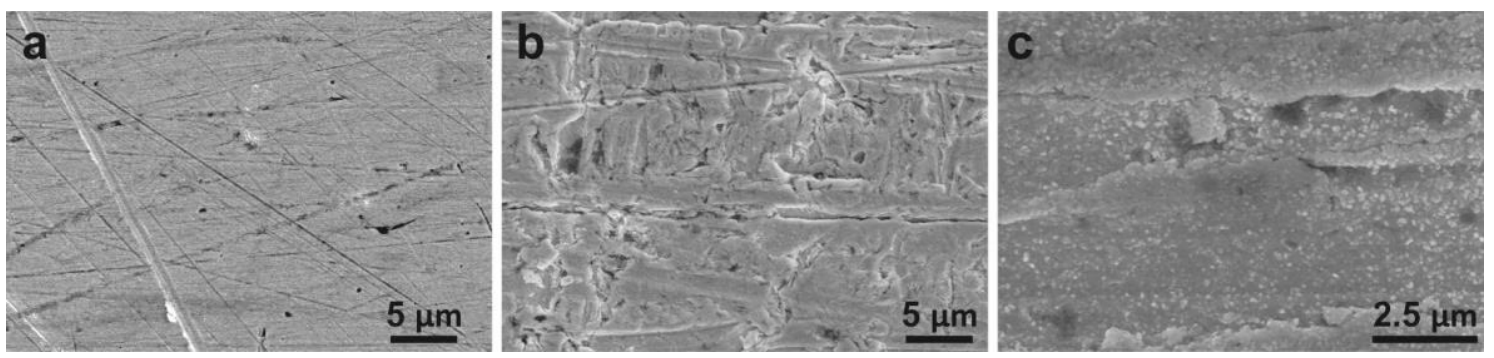

Fig. 2. SEM images of the surface of pure silver coupons cleaned with Pre-lim (a), thiourea- $\mathrm{H}_{3} \mathrm{PO}_{4}$ solution (b) and electrochemical reduction in $\mathrm{Na}_{3} \mathrm{H}\left(\mathrm{CO}_{3}\right)_{2}$ (c) .

\subsection{Sterling silver cleanings}

Mechanical methods (MP, MC and MT) abraded the surface of sterling silver, removing the corrosion layer and the outermost layer of unaltered metal. The final surface was smooth (Fig. 3 a), despite some linear marks and deep holes related with preparation of the coupon are still visible. Sulphur compounds were detected in these cavities showing that mechanical cleaning cannot reach them (Fig. 3 a, analysis A2). The original morphology was lost due to the abrasion.

The chemical cleaning CF and CP were the fastest methods but after six cycles, the surface acquired a yellowish tone (see colorimetric results below). The thiourea solution attacked the surface leaving it completely heterogeneous with holes in which the cleaning solution was retained (Fig. 3 b). Despite the morphology, the microanalysis of the surface was very similar to the original coupon (Fig. 3 b, analysis A3). Over the surface, isolated crystals of CuS were detected (Fig. 3 c). 

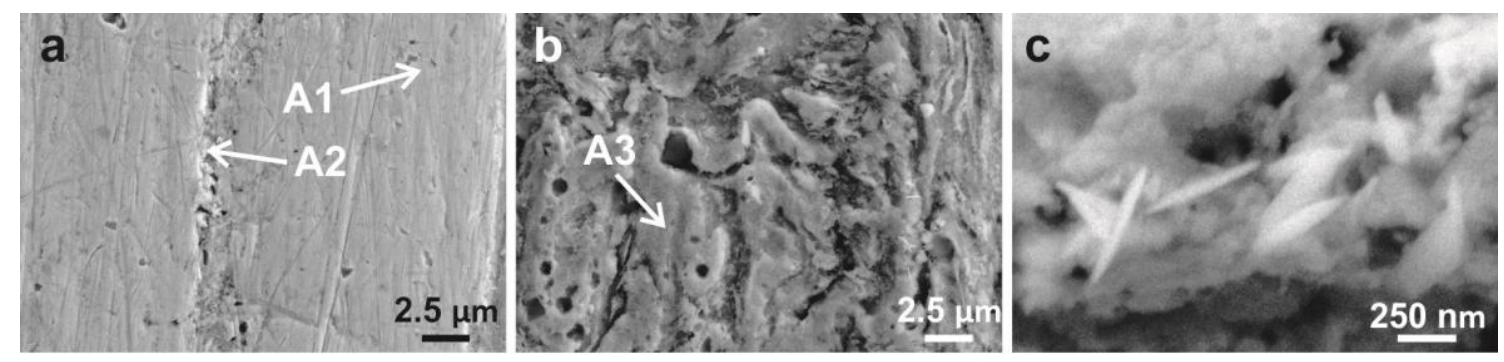

\begin{tabular}{crrc}
\hline Analysis & \multicolumn{1}{c}{ S } & \multicolumn{1}{c}{ Cu } & Ag \\
\hline A1 & -- & 4,2 & 95,8 \\
A2 & 3,8 & 12,1 & 84,1 \\
A3 & -- & 4,7 & 95,3 \\
\hline
\end{tabular}

Fig. 3. SEM images of the surface of the sterling silver coupons cleaned with $\mathrm{CaCO}_{3}(\mathrm{a})$ and thiourea$\mathrm{HCOOH}$ solution (b). Crystals of CuS on sterling silver coupons cleaned with thiourea-HCOOH solution(c). The enclosed table displays EDX microanalysis results (wt. \%).

The electrochemical cleaning of sterling silver coupons was rejected since reduction of CuS to metallic copper and its re-deposition on the silver surface left it totally covered by a dark brownish layer. This shortcoming can be avoided by using a combination of cleaning techniques, for instance, removing copper compounds in a first step by a chelating agent and electrochemically reducing the remaining silver compounds in a second step. Indeed, combination of different techniques is common in actual conservation practice. However, the aim of this paper was not to cover all possible combinations of techniques but to provide individual assessment of the treatments to give the conservators-restorers scientific evidence for their work.

\subsection{Surface morphology}

AFM results were in agreement with SEM. The original pure silver surface showed sharp edges related with the coupon preparation (Fig. $4 \mathrm{P}_{0}$ ). After tarnishing, the surface was homogeneously covered with several deposits of $\mathrm{Ag}_{2} \mathrm{~S}$ (over $150 \mathrm{~nm}$ of diameter and $15 \mathrm{~nm}$ of height) (Fig. $4 \mathrm{P}_{1}$ ). Mechanical cleaning left the pure silver surface smooth, except for several deposits located inside the deepest scratches which were related with $\mathrm{Ag}_{2} \mathrm{~S}$ deposits and remains of abrasives (Fig. $4 \mathrm{MC}$ ). Coupons cleaned by chemical procedures showed a completely heterogeneous surface due to the reaction of the thiourea with silver which enlarged the original scratches (Fig. 2 b, Fig. 4 CP). The electrochemical procedures left the surface homogeneously covered by twinning deposits with $\sim 300 \mathrm{~nm}$ of diameter and $\sim 40 \mathrm{~nm}$ of height (Fig. $4 \mathrm{ES}$ ). This morphology was related with the electrochemical reduction of the corrosion products. During tarnishing, sulphur vapors reacted with silver forming spherical deposits of $\mathrm{Ag}_{2} \mathrm{~S}$. The electrochemical reduction fixed the silver on the surface preserving the $\mathrm{Ag}_{2} \mathrm{~S}$ deposits morphology. On the following tarnishing cycle, new $\mathrm{Ag}_{2} \mathrm{~S}$ deposits were formed in the surface, between the previous ones, favoring their interconnection. 

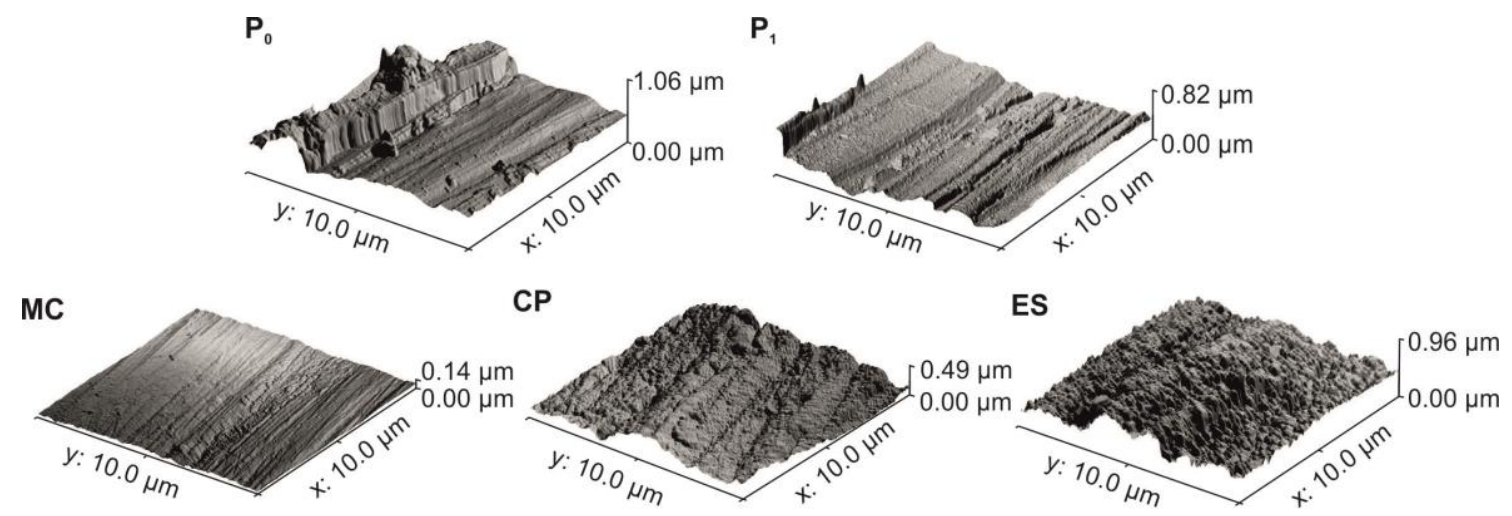

Fig. 4. AFM images $(10 \times 10 \mu \mathrm{m})$ of the surface of pure silver coupons: original $\left(P_{0}\right)$, tarnished $\left(P_{1}\right)$, mechanically cleaned with carbonate (MC), chemically with thiourea- $\mathrm{H}_{3} \mathrm{PO}_{4}$ solution (CP) and electrochemically in $\mathrm{Na}_{3} \mathrm{H}\left(\mathrm{CO}_{3}\right)_{2}$ (ES).

\subsection{Cleaning assessment}

The efficacy of cleaning procedures in removing all remains of sulphur compounds was evaluated by XPS. An ideal cleaning should be able to eliminate $S$ from the surface of the metal, without leaving any other alien elements from the cleaning treatment. In all cases, $\mathrm{S}_{2 p}$ photoemission peak shows a maximum at $\sim 161.8 \mathrm{eV}$, corresponding to silver sulphide. All cleaning methods partially removed the sulphur content in comparison with the tarnished silver coupon, which presented the highest $S_{2 p}$ peak (Fig. 5 a and b). It is remarkable that, in spite of removing significant amounts of base metal, the mechanical abrasion with calcium carbonate (MC) and Pre-lim (MP) were the less effective methods because they were not able to remove the silver sulphide trapped in the deepest scratches and holes. SEM and AFM observations confirmed it (Fig. $3 \mathrm{~A} 1$ and A2, Fig. 4 MC). MT was the most effective mechanical procedure for sterling silver, because it removed sulphur almost completely (Fig. 5 b, MT), but it is a very aggressive treatment. The chemical cleaning procedures were fast and effective removing sulphur deposits (Fig. $5 \mathrm{a}$ and b, CP and CF). Although, XPS identified the presence of alien elements on the surface of the silver that were not removed by rinsing: residues of thiourea-acid solutions (Fig. $6 \mathrm{a}$ and b). The $\mathrm{N}_{1 \mathrm{~s}}$ peak at $\sim 399.5 \mathrm{eV}$ was related with the thiourea $\left(\mathrm{CH}_{4} \mathrm{~N}_{2} \mathrm{~S}\right)$ nitrogen and the $\mathrm{P}_{2 \mathrm{p}}$ peak at $\sim 134.0 \mathrm{eV}$ with the phosphorous from $\mathrm{H}_{3} \mathrm{PO}_{4}$ used to acidify the thiourea solution. $\mathrm{P}$ and $\mathrm{N}$ form strong chemical bonds with the surface, so even a thorough rinsing might be ineffective to completely remove these residues. The electrochemical procedures were the most effective cleaning methods for pure silver coupons (Fig. 5 a). In particular, the procedure EN was the method which left less sulphur compounds on the pure silver surface. The electrochemical cleaning of sterling silver coupons was rejected since reduction of CuS covered them by a dark brownish layer. 

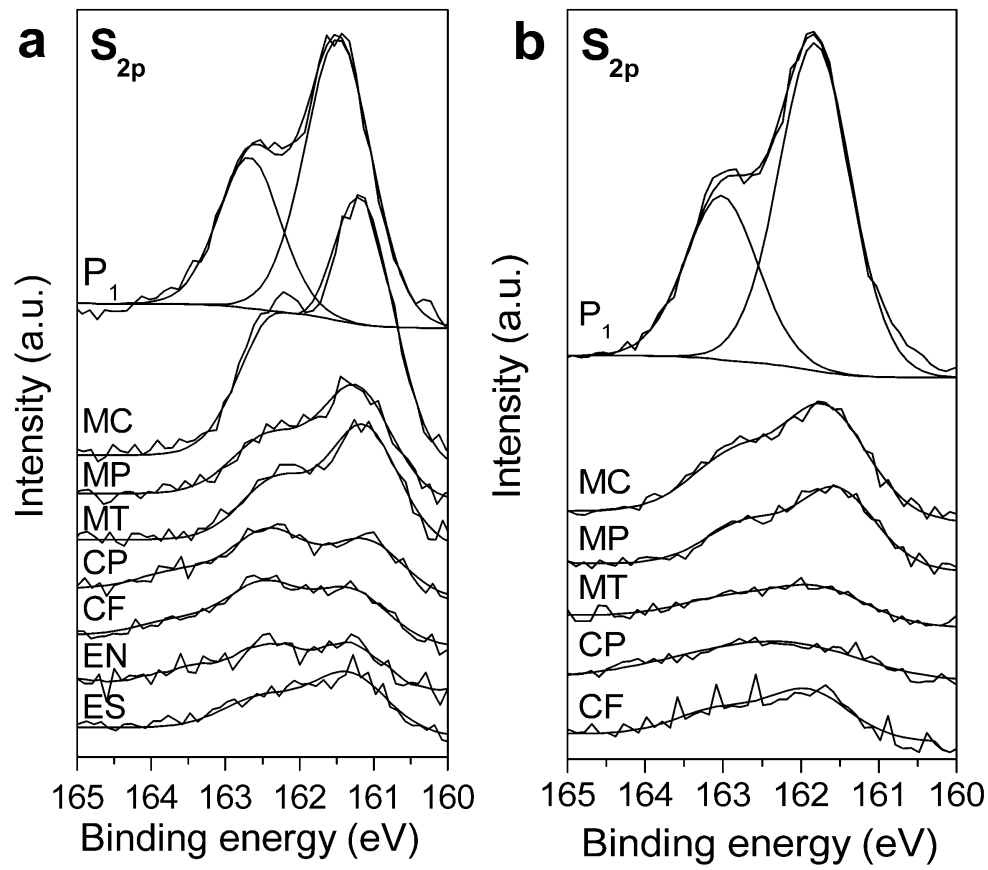

Fig. 5. XPS S $2 p$ spectra of pure silver (a) and sterling silver (b) coupons tarnished and cleaned after 6 cycles by mechanical procedure with calcium carbonate (MC), Pre-lim (MP) and polishing (MT); chemical methods with thiourea- $\mathrm{H}_{3} \mathrm{PO}_{4}$ solution (CP) and thiourea- $\mathrm{HCOOH}$ solution (CF); and electrochemical cleanings with $\mathrm{NaNO}_{3}(\mathrm{EN})$ and $\mathrm{Na}_{3} \mathrm{H}\left(\mathrm{CO}_{3}\right)_{2}$ (ES) as electrolyte.
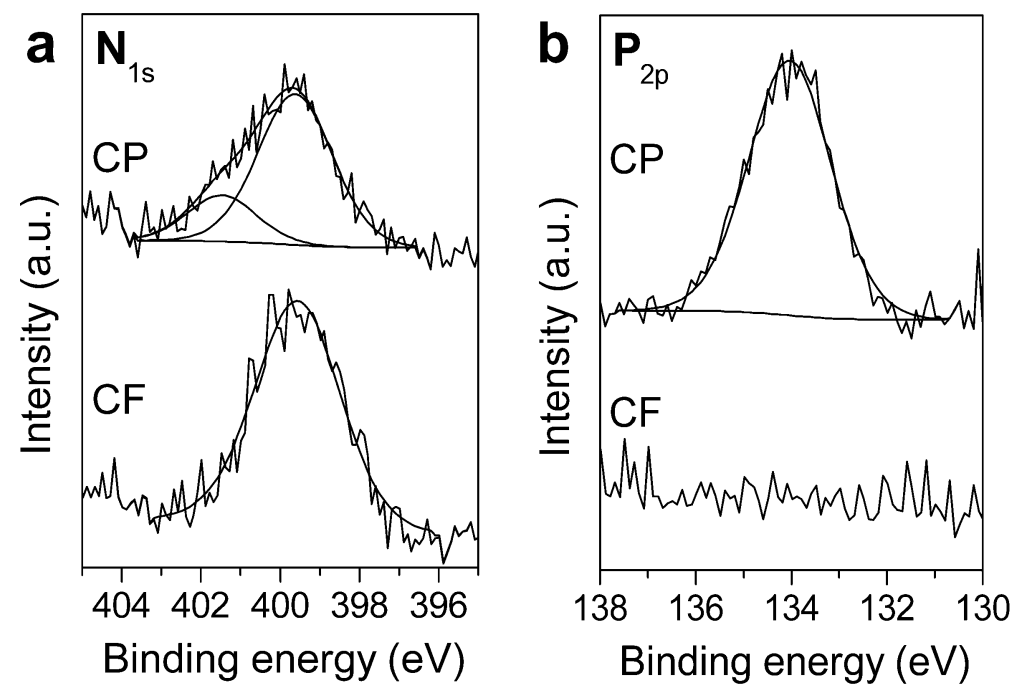

Fig. 6. XPS spectra of sterling silver coupons tarnished and cleaned after 6 cycles by chemical methods with thiourea- $\mathrm{H}_{3} \mathrm{PO}_{4}$ solution (CP) and thiourea- $\mathrm{HCOOH}$ solution (CF): $\mathrm{N}_{1 s}(a)$ and $\mathrm{P}_{2 p}(b)$.

\subsection{Mass variation}

The mass depletion of pure silver coupons was directly related with the cleaning methods. The ideal cleaning method should be able to remove tarnishing without losing a significant amount of the base metal. The most abrasive method was MT, which removed $\sim 1.0 \%$ of mass after 6 cycles of tarnishing and cleaning in pure silver coupons (Fig. 7 a). The remaining mechanical treatments, MP and MC, were mild abrasives and they produce a mass loss of around half of the depleted mass by MT ( $0.4 \%$ of mass in 6 cycles). Thiourea-acid solutions (CP and CF) produced a loss of silver mass similar to mild abrasives (Fig. 7 a). CP was slightly more reactive 
than $\mathrm{CF}$, and extracted $0.1 \%$ more mass of silver. However, the morphology of the attack is different: while mechanical cleanings produce a uniform loss of metal in the whole surface, chemical cleanings with thiourea produce localized corrosion of the surface. On the other side, electrochemical cleaning methods were the less aggressive treatments from the point of view of mass loss, since they showed an almost constant mass (Fig. 7 a) after the whole 6 cycles because the silver sulphide was reduced to metallic silver with a minimum loss of material.

Similar results were observed in sterling silver coupons (Fig. 7 b). MP and MC induced a similar loss of mass ( $\sim .3 \%$ of mass in 6 cycles), as well as the thiourea-acid solutions ( $0.2 \%$ of mass). MT was the most abrasive cleaning method ( $1.5 \%$ of mass) (Fig. 7 b), especially during the fourth cycle in which $42 \mathrm{mg}$ were removed. It is important to emphasize that manual procedures can produce not homogeneous cleanings, as they are more subjective. This is especially delicate in polishing because it is an aggressive procedure and can produce punctual and uncontrolled losses of mass. For sterling silver, electrochemical methods were not tested due to the already mentioned re-deposition of copper.
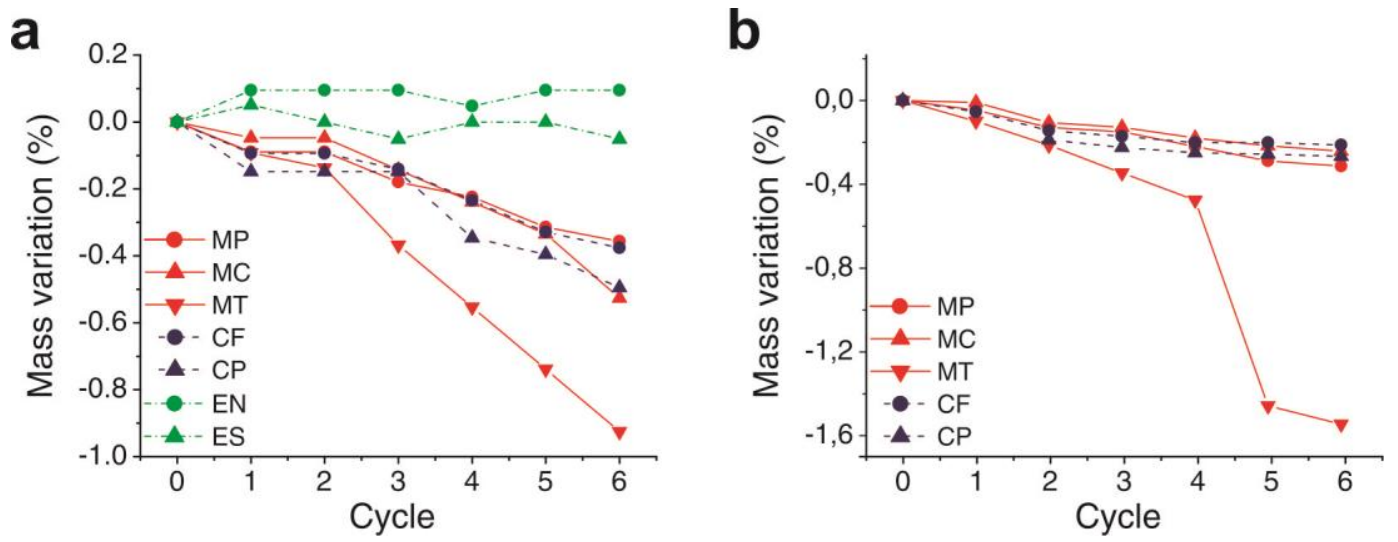

Fig. 7. Mass variation in function of the cycle number for pure silver (a) and sterling silver (b).

For conservation practice, it its especially relevant that mechanical treatments, which are considered to be more controllable [1], remove as much base metal as the chemical ones, and produce a significant change in the surface morphology as shown in Fig. 4.

\subsection{Color and luminosity variation}

The visual aspect after the cleaning and the re-tarnishing process was evaluated by the change of color and luminosity. It is important to remember that the main reason for cleaning tarnished silver is to restore its original visual appearance, so the ideal cleaning treatment should not show color changes when compared to the original samples. The color of the coupons cleaned by mechanical treatments was similar to the original silver (Fig. 8 a), because the abrasives removed the outer layer of the coupon leaving a completely new silver surface. In the case of chemical treatments, the silver surface was progressively altered inducing a yellowish tone (Fig. 8 a). The final color of the coupon cleaned with $\mathrm{CP}$, whose surface was more altered than the coupon cleaned with $\mathrm{CF}$, presented a higher $\mathrm{b}^{*}$ component, that means, a more yellowish tone (Fig. 8 a). Similar results were observed in pure silver samples.

The re-tarnishing process was evaluated by the difference of luminosity during the tarnishing $\left(\Delta L^{*}=\mid L^{*}\right.$ tarnished silver $-L^{*}$ clean silver $\left.\mid\right)$ (Fig. 8 b). The samples cleaned by mechanical 
procedures showed a progressive increase in $\Delta \mathrm{L}^{*}$, related with a more intense re-tarnishing for the same time of exposition to the sulphur atmosphere. The mechanical abrasives left a completely new and active surface which could react with the sulphur gaseous. Additionally, as has been shown by XPS and SEM, sulphur compounds remain retained in the scratches and pores of silver, and might react with the freshly exposed metal. On the other side, the retarnishing process of coupons cleaned by chemical procedures was progressively decreased. This may be attributed to the remains of thiourea-acid solution showed by XPS. Organic compounds containing nitrogen, such as benzotriazole, are known to be corrosion inhibitors due to their capability of bonding to the metal surface and blocking reaction sites, so to some extent the thiourea residues can protect silver from reaction with the sulphur gases [30].
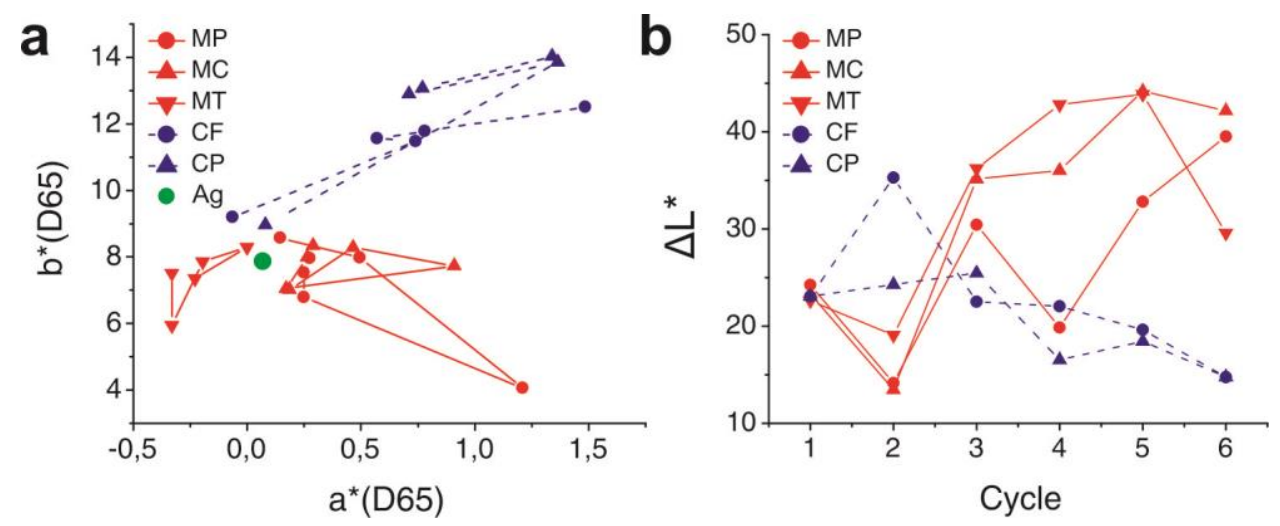

Fig. 8. Chromaticity coordinates after cleaning with different treatments (a). Luminosity variation $\left(\Delta L^{*}=\mid L^{*}\right.$ tarnished silver $-L^{*}$ clean silver $\left.\mid\right)$ with the cycle number in sterling silver coupons $(b)$.

\section{Conclusions}

This research has demonstrated that the efficiency of cleaning silver artifacts depends on the procedure applied and the composition of silver. None of the tested procedures attained optimal results regarding all evaluated aspects: visual appearance, base metal loss, residues left on the surface and re-tarnishing. Four chemical methods (thiourea $8 \% \mathrm{w} / \mathrm{w}$, formic acid $10 \% \mathrm{v} / \mathrm{v}$, DTPA pentasodium salt $10 \% \mathrm{w} / \mathrm{w}+$ Triton X-100 1.5\% v/v , and EDTA $10 \% \mathrm{w} / \mathrm{w}$ ) were inefficient to remove silver tarnishing. Mechanical procedures removed silver sulphide by abrasion but they left a smooth surface and remains of $\mathrm{Ag}_{2} \mathrm{~S}$ inside the deepest scratches and holes. Also, the fastest re-tarnishing process was observed in mechanically cleaned coupons: the completely new and active surface exposed after each cleaning cycle quickly reacts with the gaseous sulphur. Polishing with a rotary tool and a rubber point was the most aggressive procedure because it can produce punctual and uncontrolled mass losses. Chemical cleaning with thiourea-acid solutions was very fast, nevertheless the surface appeared completely attacked after six cycles of tarnishing/cleaning, and remains of the solution were detected on the surface. These residual compounds seem to act as corrosion inhibitors, hindering tarnishing in subsequent cycles. Electrochemical cleaning was an effective cleaning method for pure silver coupons, producing no significant loss of base metal, although it left a microscopically rough surface; while in sterling silver, the electrochemical reduction and redeposition of copper left a dark brownish layer, making this procedure unacceptable for this material, unless it is combined with other methods. Regarding the color and luminosity of the 
coupon, silver cleaned with mechanical procedures presented similar color to the original silver, as opposed to chemical methods which showed a yellowish tone.

\section{Acknowledgments}

The authors acknowledge to P. Navarro the silver $99 \mathrm{wt} \%$ for the experiment, to I. Llorente the AFM and XPS measurements and to O. García the colorimetric measurements. This work has been partially funded by project CREMEL Ref. HAR2011-22402 and the pre-doctoral FPI grant BES-2012-052716 from the Spanish Ministry of Economy and Competitiveness (MINECO), and GEOMATERIALES 2-CM Program Ref. S2013/MIT-2914. Finally, the authors want to mention the professional support of the Spanish Network on Science and Technology for the Conservation of Cultural Heritage (TechnoHeritage).

\section{Bibliography}

[1] V. Costa, The deterioration of silver alloys and some aspects of their conservation, Reviews in Conservation, 2 (2001) 18-34.

[2] L.S. Selwyn, Historical silver: Storage, display, and tarnish removal, Journal of International Institute for Conservation of Historic and Artistic Works, 15 (1990) 12-22.

[3] T. Graedel, Corrosion mechanisms for silver exposed to the atmosphere, Journal of the Electrochemical Society, 139 (1992) 1963-1970.

[4] J.P. Franey, G.W. Kammlott, T.E. Graedel, The corrosion of silver by atmospheric sulfurous gases, Corrosion Science, 25 (1985) 133-143.

[5] D. Pope, H.R. Gibbens, R.L. Moss, The tarnishing of Ag at naturally-occurring $\mathrm{H} 2 \mathrm{~S}$ and $\mathrm{SO} 2$ levels, Corrosion Science, 8 (1968) 883-887.

[6] G. Wharton, S.L. Maish, W.S. Ginell, A comparative study of silver cleaning abrasives, Journal of the American Institute for Conservation, 29 (1990) 13-31.

[7] L.S. Selwyn, C.G. Costain, Evaluation of silver-cleaning products, Journal of the International Institute for Conservation-Canadian Group: J. IIC-CG, 16 (1991) 3-16.

[8] J. Contreras-Vargas, J.L. Ruvalcaba-Sil, F.J. Rodríguez-Gómez., Effects of the cleaning of silver with acidified thiourea solutions, in: Conference proceedings of Metal 2013, Historic Scotland and International Council of Museums, Edinburgh, 2013, pp. 223-228.

[9] E. Cano, D. Lafuente, D.M. Bastidas, Use of EIS for the evaluation of the protective properties of coatings for metallic cultural heritage: A review, Journal of Solid State Electrochemistry, 14 (2010) 381-391.

[10] F. Dalard, Y. Gourbeyre, C. Degrigny, Chloride removal from archaeological cast iron by pulsating current, Studies in Conservation, 47 (2002) 117-121.

[11] C. Degrigny, R. Le Gall, Conservation of ancient lead artifacts corroded in organic acid environments: Electrolytic stabilization/consolidation, Studies in Conservation, 44 (1999) 157169.

[12] C. Degrigny, M. Wéry, V. Vescoli, J.M. Blengino, Alteration et nettoyage de pieces en argent dore, Studies in Conservation, 41 (1996) 170-178.

[13] A. Doménech, M.T. Doménech-Carbó, T. Pasies, M.C. Bouzas, Application of modified tafel analysis to the identification of corrosion products on archaeological metals using voltammetry of microparticles, Electroanalysis, 23 (2011) 2803-2812.

[14] A. Doménech, M.T. Doménech-Carbó, T. Pasies, M. delCarmenBouzas, Modeling Corrosion of Archaeological Silver-Copper Coins Using the Voltammetry of Immobilized Particles, Electroanalysis, 24 (2012) 1945-1955.

[15] A. Doménech-Carbõ, M.T. Doménech-Carbõ, S. Capelo, T. Pasíes, I. Martínez-Lázaro, Dating archaeological copper/bronze artifacts by using the voltammetry of microparticles, Angewandte Chemie - International Edition, 53 (2014) 9262-9266. 
[16] A. Doménech-Carbó, M.T. Doménech-Carbó, M.A. Peiró-Ronda, I. Martínez-Lázaro, J. Barrio-Martín, Application of the voltammetry of microparticles for dating archaeological lead using polarization curves and electrochemical impedance spectroscopy, Journal of Solid State Electrochemistry, 16 (2012) 2349-2356.

[17] A. Doménech-Carbó, M. Lastras, F. Rodríguez, E. Cano, J. Piquero-Cilla, L. Osete-Cortina, Monitoring stabilizing procedures of archaeological iron using electrochemical impedance spectroscopy, Journal of Solid State Electrochemistry, 18 (2014) 399-409.

[18] E. Cano, D.M. Bastidas, V. Argyropoulos, S. Fajardo, A. Siatou, J.M. Bastidas, C. Degrigny, Electrochemical characterization of organic coatings for protection of historic steel artefacts, Journal of Solid State Electrochemistry, 14 (2010) 453-463.

[19] E. Cano, A. Crespo, D. Lafuente, B. Ramirez Barat, A novel gel polymer electrolyte cell for insitu application of corrosion electrochemical techniques, Electrochemistry Communications, 41 (2014) 16-19.

[20] J. Novakovic, P. Vassillou, E. Gergiza, Electrochemical cleaning of artificially tarnished silver, Internacional Journal of Electrochemical Science, 8 (2013) 7223-7232.

[21] M. Bernard, E. Dauvergne, M. Evesque, M. Keddam, H. Takenouti, Reduction of silver tarnishing and protection against subsequent corrosion, Corrosion science, 47 (2005) 663-679.

[22] V. Costa, M. Dubus, Impact of the environmental conditions on the conservation of metal artifacts: an evaluation using electrochemical techniques, Museum microclimates. The National Museum of Denmark, Copenhagen, (2007) 63-65.

[23] C. Degrigny, E. Tanguy, R. Le Gall, V. Zafiropulos, G. Marakis, Laser cleaning of tarnished silver and copper threads in museum textiles, Journal of Cultural Heritage, 4 (2003) 152-156.

[24] J.M. Lee, J. Yu, Y. Koh, Experimental study on the effect of wavelength in the laser cleaning of silver threads, Journal of Cultural Heritage, 4 (2003) 157-161.

[25] E.G. Ioanid, A. Ioanid, D.E. Rusu, F. Doroftei, Surface investigation of some medieval silver coins cleaned in high-frequency cold plasma, Journal of Cultural Heritage, 12 (2011) 220-226.

[26] A.-M. Hacke, C. Carr, A. Brown, D. Howell, Investigation into the nature of metal threads in a Renaissance tapestry and the cleaning of tarnished silver by UV/Ozone (UVO) treatment, Journal of materials science, 38 (2003) 3307-3314.

[27] UNE-EN ISO 4538, Recubrimientos metálicos. Ensayo de corrosión a la tioacetamida (Ensayo TAA), in, 1996.

[28] G. Wharton, The cleaning and lacquering of Museum Silver, Newsletter of the Western Association of American Conservators (WAAC), 11 (1989) 4-5.

[29] K.N. Stafford, Sulphidation of Metals and Alloys, Met Rev (Suppl to Metals Mater), 14 (1969) 153-174.

[30] E. Cano, D. Lafuente, Corrosion inhibitors for the preservation of metallic heritage artefacts, in: Corrosion and Conservation of Cultural Heritage Metallic Artefacts, Elsevier Ltd, 2013, pp. 570-594. 